\title{
Influence of Light Intensity on Surface Free Energy and Dentin Bond Strength of Core Build-up Resins
}

\author{
Y Shimizu • A Tsujimoto $\bullet$ T Furuichi \\ T Suzuki $\bullet$ K Tsubota $\bullet$ M Miyazaki \\ JA Platt
}

\section{Clinical Relevance}

The surface free energy and dentin bond strength of the dual-cure core build-up systems tested in this study were affected by the light intensity of the curing unit. When using dualcure core build-up systems, practitioners need to consider the light intensity of the curing unit to achieve the optimal bond strength.

\section{SUMMARY}

Objective: We examined the influence of light intensity on surface free energy characteristics and dentin bond strength of dual-cure direct core build-up resin systems.

Yuske Shimizu, DDS, graduate student, Chiyoda-Ku, Japan

Akimasa Tsujimoto, DDS, PhD, assistant professor, Operative Dentistry, Nihon University School of Dentistry, Tokyo, Japan

Tetsuya Furuichi, DDS, graduate student, Chiyoda-Ku, Japan Takayuki Suzuki, DDS, graduate student, Chiyoda-Ku, Japan Keishi Tsubota, DDS, PhD, assistant professor, Chiyoda-Ku, Japan

*Masashi Miyazaki DDS, PhD, professor, Operative Dentistry, Nihon University School of Dentistry, Tokyo, Japan

Jeffrey A Platt, DDS, MS, associate professor, Restorative Dentistry, Indiana University, Indianapolis, IN, USA

*Corresponding author: 1-8-13, Kanda-Surugadai, ChiyodaKu, Tokyo 101-8310, Japan; e-mail: miyazaki.masashi@ nihon-u.ac.jp

DOI: $10.2341 / 13-283-\mathrm{L}$
Methods: Two commercially available dualcure direct core build-up resin systems, Clearfil DC Core Automix with Clearfil Bond SE One and UniFil Core EM with Self-Etching Bond, were studied. Bovine mandibular incisors were mounted in acrylic resin and the facial dentin surfaces were wet ground on 600-grit silicon carbide paper. Adhesives were applied to dentin surfaces and cured with light intensities of 0 (no irradiation), 200, 400, and 600 $\mathrm{mW} / \mathrm{cm}^{2}$. The surface free energy of the adhesives (five samples per group) was determined by measuring the contact angles of three test liquids placed on the cured adhesives. To determine the strength of the dentin bond, the core build-up resin pastes were condensed into the mold on the adhesive-treated dentin surfaces according to the methods described for the surface free energy measurement. The resin pastes were cured with the same light intensities as those used for the adhesives. Ten specimens per group were stored in water maintained at $37^{\circ} \mathrm{C}$ for 24 hours, after which 
they were shear tested at a crosshead speed of $1.0 \mathrm{~mm} / \mathrm{minute}$ in a universal testing machine. Two-way analysis of variance (ANOVA) and a Tukey-Kramer test were performed, with the significance level set at 0.05 .

Results: The surface free energies of the adhesive-treated dentin surfaces decreased with an increase in the light intensity of the curing unit. Two-way ANOVA revealed that the type of core build-up system and the light intensity significantly influence the bond strength, although there was no significant interaction between the two factors. The highest bond strengths were achieved when the resin pastes were cured with the strongest light intensity for all the core build-up systems. When polymerized with a light intensity of $200 \mathrm{~mW} / \mathrm{cm}^{2}$ or less, significantly lower bond strengths were observed.

Conclusions: The data suggest that the dentin bond strength of core build-up systems are still affected by the light intensity of the curing unit, which is based on the surface free energy of the adhesives. On the basis of the results and limitations of the test conditions used in this study, it appears that a light intensity of $>400$ $\mathrm{mW} / \mathrm{cm}^{2}$ may be required for achieving the optimal dentin bond strength.

\section{INTRODUCTION}

Selection of an appropriate adhesive system and a core build-up resin for the restoration of endodontically treated teeth is crucial for the success of treatment. Dual-cure resins have been developed in an attempt to overcome the limitations of chemicalcured and light-cured resins by incorporating a redox initiator system in addition to the photo initiator. ${ }^{1}$ It has been reported, however, that dualcure resins have poorer mechanical properties when the polymerization reaction is limited to a chemicalcure mode alone. ${ }^{2,3}$ Although important for resin pastes, proper light irradiation of the adhesive is also required to achieve the optimal dentin bond strength.

Previous studies revealed that the bond strength value was higher when photo-cure bonding agents with sufficient light irradiation time were used for bonding to root canal dentin than when dual-cure systems were used. ${ }^{4}$ The apical region of the root canal poses additional difficulties in terms of light curing, which is likely to be the main reason for the lower bond strength in this region. ${ }^{5}$ Because the accessibility of light energy passing through a deep and narrow root canal space is restricted, the bond strength gradually decreases from the coronal to the apical surface of the root canal. ${ }^{6}$ Therefore, light irradiation of an adhesive seems to be important for core build-up systems to achieve good adhesion to root canal dentin. ${ }^{7}$ Because there is little information on the mechanism by which light irradiation of adhesives affects the dentin bond strength of dualcure direct core build-up systems, determining the influence of light intensity on the dentin bonding characteristics of these resin systems is required.

Wettability of the conditioned adherent surface with adhesives is important for dentin bonding regardless of the mechanism of bonding (ie, chemical, micromechanical interlocking, or a combination). ${ }^{8}$ Proper infiltration and polymerization of adhesive in combination with a core build-up resin is required for the success of treatment because bonding to the root canal surface is always challenged by polymerization shrinkage of the core buildup resins. ${ }^{9,10}$ The strength of the bond between dentin and the resin composite depends on several factors, including the characteristics of the dentinal substrate and the ability of the adhesives to wet the adherend. ${ }^{11}$ Measurements of the contact angles on the adherent surfaces provide information about the surface free energies that relate to the bonding characteristics of the solids. ${ }^{12}$ It is expected that analysis of surface free energy will provide more insight into the evolution of the adhesive performance of direct core build-up systems.

This study aimed to examine the influence of the light intensity of the curing unit on the surface free energy of adhesive-treated dentin and the bond strength of dual-cure direct core build-up systems to bovine dentin. The null hypothesis was that the dentin bond strength and polymerization behavior of dual-cure resin core build-up systems are not affected by the light intensity of the curing unit.

\section{METHODS AND MATERIALS}

\section{Core Build-up System}

Two dual-cure resin core build-up systems, Clearfil DC Core Automix (DC; Kuraray Noritake Dental Inc, Tokyo, Japan) and UniFil Core EM (UC; GC Corp, Tokyo, Japan), were used in combination with the corresponding manufacturer-provided adhesives, Clearfil Bond SE One (Kuraray Noritake Dental Inc) and Self-Etching Bond (GC Corp) (Table 1). A visible-light curing unit (Optilux 400, Demetron/ Kerr, Danbury, CT, USA) was connected to a 
Table 1: Core Build-up Systems Tested in This Study

\begin{tabular}{|lll|}
\hline \multicolumn{1}{|c|}{$\begin{array}{c}\text { Core Build-up System (Manufacturer); } \\
\text { Code }\end{array}$} & \multicolumn{1}{c|}{ Adhesive System (Lot No.) } & Resin Paste (Lot No.) \\
\hline $\begin{array}{l}\text { Clearfil DC Core Automix One (Kuraray } \\
\text { Noritake Dental Inc, Tokyo, Japan); DC }\end{array}$ & $\begin{array}{l}\text { Clearfil Bond SE One (00005A): MDP, Bis- } \\
\text { GMA, HEMA, ethanol, water, filler, CQ }\end{array}$ & $\begin{array}{l}\text { Clearfil DC Core Automix (One 00021AA): } \\
\text { Bis-GMA, TEGDMA, dimethacrylate, filler, } \\
\text { photo/chemical initiator }\end{array}$ \\
\hline $\begin{array}{lll}\text { UniFil Core EM (GC Corp, Tokyo, Japan); } \\
\text { UC }\end{array}$ & $\begin{array}{l}\text { Self-Etching Bond (A: 1208011, B: } \\
1208011): \text { 4-MET, ethanol, water } \\
\text { methacrylate monomer, photo/chemical } \\
\text { initiator }\end{array}$ & $\begin{array}{l}\text { UniFil Core EM (1208011): UDMA, } \\
\text { dimethacrylate, fluoroaluminosilicate glass, } \\
\text { photo/chemical initiator }\end{array}$ \\
\hline $\begin{array}{l}\text { Abbreviations: Bis-GMA, 2, 2bis[4-(2-hydroxy-3-methacryloyloxypropoxy)]phenyl; CQ, dl-camphorquinone; 4-MET, 4-methacryloyloxyethyl trimellitate; HEMA, 2- } \\
\text { hydroxyethyl methacrylate; MDP, 10-methacryloxydecyl dihydrogen phosphate TEGMDA, triethylene glycol dimethacrylate; UDMA, urethane dimethacrylate. }\end{array}$ \\
\hline
\end{tabular}

variable-voltage transformer (Type S-130-10, Yamabishi Electric Co, Tokyo, Japan). The light intensities used were $100,200,400$, and $600 \mathrm{~mW} / \mathrm{cm}^{2}$; these values were determined using a dental curing radiometer (Model 100, Demetron/Kerr). The curing unit was placed on a jig to maintain the distance between the light tip end and the specimen surface (2 $\mathrm{mm})$.

\section{Surface Free Energy}

A total of 40 mandibular incisors from 2- to 3-yearold cattle were used as substitutes for human teeth. ${ }^{13}$ After separating the roots with a low-speed diamond saw (Isomet 1000, Buehler Ltd, Lake Bluff, IL, USA), the pulps were extirpated and the pulp chamber of each tooth was filled with cotton to avoid penetration of the embedding medium. The labial surfaces of the bovine incisors were ground with wet 240-grit silicon carbide ( $\mathrm{SiC}$ ) paper to produce a flat dentin surface (Ecomet 4, Buehler Ltd). Each tooth was then mounted in self-curing acrylic resin (Trey Resin II, Shofu Inc, Kyoto, Japan) to expose the flattened area and placed in tap water to decrease the temperature rise from the exothermic polymerization reaction of the acrylic resin. The final finish of the dentin surface was accomplished by grinding on wet 600-grit $\mathrm{SiC}$ paper. After ultrasonic cleaning in distilled water for one minute to eliminate debris, the surfaces were washed with tap water and dried with oil-free compressed air.

For the DC, one drop of Clearfil Bond SE One was applied on the dentin surface for 10 seconds. After blowing with mild air for five seconds, the adhesives were light polymerized for 10 seconds. For the UC, equal amounts of Self-Etching Bond liquids were mixed for five seconds and applied on the dentin for 30 seconds. After blowing strongly with air for 10 seconds, the adhesives were light polymerized for 10 seconds. Light irradiation was performed at intensities of 0 (no irradiation), 200, 400, and $600 \mathrm{~mW} / \mathrm{cm}^{2}$.
The surface free energies of five specimens per group for each adhesive-treated dentin surface were determined by measuring the contact angle on the surface for three test liquids, namely distilled water, 1-bromonaphthalen, and ethylene glycol, each of which has known surface free energy parameters. The Drop Master DM500 apparatus (Kyowa Interface Science, Saitama, Japan) was fitted with a charge-coupled device camera, which allowed automatic measurement of the contact angles (Figure 1). ${ }^{14}$
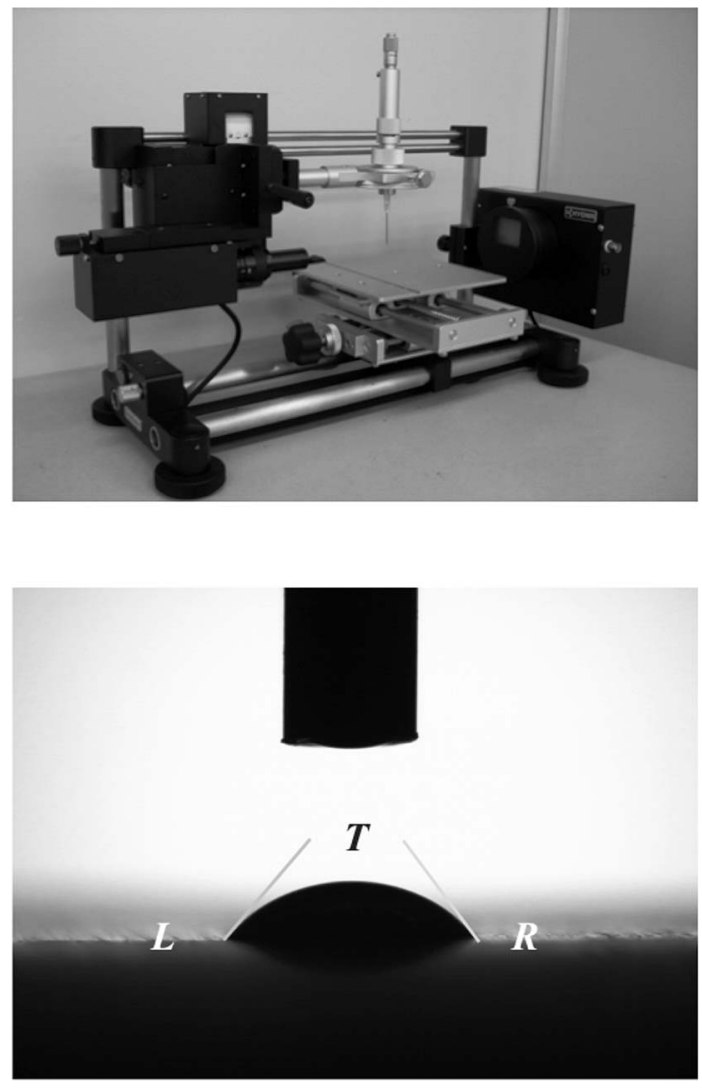

Figure 1. Drop Master DM500 apparatus (Kyowa Interface Science) fitted with a charge-coupled device camera allowing automatic measurements of the contact angles to be made. 
For each test liquid, the equilibrium contact angle $(\theta)$ was measured for five specimens of each adhesive using the sessile-drop method at $23^{\circ} \mathrm{C} \pm 1^{\circ} \mathrm{C}$. The surface free energy parameters of the solids were then determined on the basis of the fundamental concepts of wetting. ${ }^{15}$

The Young-Dupré equation describes the work of adhesion (W) for a solid (S) and a liquid (L) that are in contact as follows:

$$
\mathrm{W}_{\mathrm{SL}}=\gamma_{\mathrm{L}}+\gamma_{\mathrm{S}}-\gamma_{\mathrm{SL}}=\gamma_{\mathrm{L}}(1+\cos \theta)
$$

Here, $\gamma_{\mathrm{SL}}$ is the interfacial free energy between the solid and liquid, $\gamma_{L}$ is the surface free energy of the liquid, and $\gamma_{S}$ is the surface free energy of the solid.

By extending the Fowkes equation, the $\gamma_{\mathrm{SL}}$ is expressed as follows:

$$
\begin{aligned}
& \gamma_{\mathrm{SL}}=\gamma_{\mathrm{L}}+\gamma_{\mathrm{S}}-2\left(\gamma_{\mathrm{L}}^{\mathrm{d}} \gamma_{\mathrm{S}}^{\mathrm{d}}\right)^{1 / 2}-2\left(\gamma_{\mathrm{L}}^{\mathrm{p}} \gamma_{\mathrm{S}}^{\mathrm{p}}\right)^{1 / 2}-2\left(\gamma_{\mathrm{L}}^{\mathrm{h}} \gamma_{\mathrm{S}}^{\mathrm{h}}\right)^{1 / 2} \\
& \gamma_{\mathrm{L}}=\gamma_{\mathrm{L}}^{\mathrm{d}}+\gamma_{\mathrm{L}}^{\mathrm{p}}+\gamma_{\mathrm{L}}^{\mathrm{h}}, \gamma_{\mathrm{S}}=\gamma_{\mathrm{S}}^{\mathrm{d}}+\gamma_{\mathrm{S}}^{\mathrm{p}}+\gamma_{\mathrm{S}}^{\mathrm{h}}
\end{aligned}
$$

where $\gamma_{L}^{\mathrm{d}}, \gamma_{\mathrm{L}}^{\mathrm{p}}$, and $\gamma_{\mathrm{L}}^{\mathrm{h}}$ are components of the surface free energy $(\gamma)$ arising from the dispersion force, the polar (permanent and induced) force, and the hydrogen-bonding force, respectively. The $\theta$ values were determined for the three test liquids, and the surface energy parameters of the treated dentin surfaces were calculated on the basis of equations using add-on software and the interface measurement and analysis system (FAMAS, Kyowa Interface Science).

\section{Dentin Bond Strength}

A total of 80 mandibular incisors from cattle were treated as described in the "Surface Free Energy" section. A piece of double-sided adhesive tape with a 4-mm-diameter hole was firmly attached to define the adhesive area for bonding. A Teflon mold (2-mm high, 4-mm diameter) was used to form and hold the resin pastes to the dentin surface. The dentin surfaces were treated according to the methods described for surface free energy measurements. The auto-mixed pastes were directly inserted into the mold on the adhesive-treated dentin surface, followed by light polymerization for 40 seconds with the same light intensities as those used for the adhesives.

The mold and adhesive tape were removed from the specimen 10 minutes after placement of the resin pastes. Subsequently, the specimens were stored in distilled water maintained at $37^{\circ} \mathrm{C}$ for 24 hours. The specimens in each group were tested in shear mode using a knife-edge testing apparatus in a universal testing machine (Type 4204, Instron Corp, Canton, MA, USA) at a crosshead speed of $1.0 \mathrm{~mm} / \mathrm{minute}$. The shear bond strengths were calculated in megapascals by dividing the peak load at failure by the bond surface area. After testing, the specimens were examined under an optical microscope (SZH-131, Olympus Ltd, Tokyo, Japan) at a magnification of $10 \times$ to determine the location of the bond failure. Types of failures were determined on the basis of the predominant percentage of substrate free material as follows: adhesive failure, cohesive failure in composite, and cohesive failure in dentin.

\section{Statistical Analysis}

The dentin bond strength data obtained were analyzed using a commercial statistical software package (Sigma Stat, Version 3.1, SPSS Inc, Chicago, IL, USA). Because the data were normally distributed (Kolmogorov-Smirnov test), two-way analysis of variance (ANOVA) was used to analyze the effect of the core build-up system and that of light intensity. Multiple comparisons were then conducted using the Tukey-Kramer test, with the significance level set at 0.05 .

\section{Scanning Electron Microscopy}

The resin-dentin interface was ultrastructurally observed by scanning electron microscopy (SEM). Bonded specimens from each group $(\mathrm{n}=5)$ were stored in distilled water maintained at $37^{\circ} \mathrm{C}$ for 24 hours, embedded in self-curing epoxy resin (Epon 812 , Nisshin EM, Tokyo, Japan), and stored at $37^{\circ} \mathrm{C}$ for an additional 12 hours. The embedded specimens were sectioned through the diameter of the composite resin post, and the surfaces of the cut halves were polished with an Ecomet 4/Automet 2 (Buehler Ltd) using $\mathrm{SiC}$ papers with a grit size of 600,1200 , and 4000 in succession. The surface was finally polished by a soft cloth using diamond paste (Buehler Ltd) with a grit size of $1.0 \mu \mathrm{m}$. All SEM specimens were dehydrated in ascending concentrations of tertbutanol (50\% for 20 minutes, $75 \%$ for 20 minutes, $95 \%$ for 20 minutes, and $100 \%$ for two hours) and transferred to a critical-point dryer for 30 minutes. These surfaces were subjected to Argon ion-beam etching (Type EIS-200ER, Elionix Ltd, Tokyo, Japan) for 30 seconds, with the ion beam (accelerating voltage, $1.0 \mathrm{kV}$; ion current density, $0.4 \mathrm{~mA} / \mathrm{cm}^{2}$ ) directed perpendicularly to the polished surface. Surfaces were coated in a vacuum evaporator (Quick 


\begin{tabular}{|c|c|c|c|c|c|}
\hline & Intensity & $Y S^{d}$ & $Y s^{p}$ & $Y s^{h}$ & YS \\
\hline & 0 & $41.1(0.2)$ & $3.1(0.7)$ & $24.9(1.7)$ & $69.1(2.1)$ \\
\hline \multirow[t]{4}{*}{ DC } & 200 & $41.1(0.1)$ & $1.8(0.5)$ & $16.4(1.1)$ & $59.3(2.0)$ \\
\hline & 400 & $39.8(0.3)$ & $0.7(0.3)]$ & $8.9(0.6) 7$ & $49.4(1.7)]$ \\
\hline & 600 & $39.2(0.2)$ & $0.7(0.3)]$ & $8.8(0.6)]$ & $48.7(1.6)$ \\
\hline & 0 & $41.1(0.2)$ & $5.6(0.9)$ & $21.0(1.6)$ & $67.7(2.2)$ \\
\hline \multirow[t]{3}{*}{ UC } & 200 & $41.1(0.3)$ & $3.9(0.9)$ & $17.6(1.2)$ & $62.6(2.1)$ \\
\hline & 400 & $40.0(0.4)$ & $1.4(0.6)]$ & $14.9(1.1)]$ & $56.3(2.0)]$ \\
\hline & 600 & $39.8(0.3)$ & $1.0(0.6)\rfloor$ & $14.8(1.1)$ & $55.6(1.8)]$ \\
\hline
\end{tabular}

Coater Type SC-701, Sanyu Denshi Inc, Tokyo, Japan) with a thin film of gold and observed by SEM (ERA 8800FE, Elionix Ltd) at an accelerating voltage of $10 \mathrm{kV}$. All of the specimens were observed under SEM.

\section{RESULTS}

The surface free energies and their components for the cured adhesives are shown in Table 2. The total surface free energy $\left(\gamma_{\mathrm{S}}=\gamma_{\mathrm{S}}^{\mathrm{d}}+\gamma_{\mathrm{S}}^{\mathrm{p}}+\gamma_{\mathrm{S}}^{\mathrm{h}}\right)$ values decreased with an increase in light intensity, and they were significantly lower when adhesives were irradiated with a light intensity of $>400 \mathrm{~mW} / \mathrm{cm}^{2}$. For all surfaces, the estimated $\gamma_{\mathrm{S}}^{\mathrm{d}}$ values remained relatively constant in the range of 39.2 to 41.1 $\mathrm{mJ} \cdot \mathrm{m}^{-2}$. Decreases in $\gamma_{\mathrm{S}}^{\mathrm{p}}$ and $\gamma_{\mathrm{S}}^{\mathrm{h}}$ values were observed for the specimens that were light irradiated with a stronger light intensity.

The influence of the light intensity of the curing unit on shear bond strengths is shown in Table 3 . Two-way ANOVA revealed that the type of core build-up system $(p<0.001)$ and the light intensity $(p<0.001)$ significantly influence on the bond strength, although there was no significant interaction between the two factors ( $p=0.806$ ). For both core build-up systems, greater bond strengths were achieved when a light intensity of $400 \mathrm{~mW} / \mathrm{cm}^{2}$ or greater was used. Statistically significant differences were observed between the obtained values, except

\begin{tabular}{|c|c|c|c|c|}
\hline & \multicolumn{4}{|c|}{ Light Intensity $\left(\mathrm{mW} / \mathrm{cm}^{2}\right)$} \\
\hline & 0 & 200 & 400 & 600 \\
\hline $\mathrm{DC}$ & $12.8(1.8) \mathrm{a}^{\mathrm{a} *}$ & $15.8(1.8) \mathrm{b}$ & $17.5(2.7) \mathrm{c}$ & $17.8(3.3) \mathrm{c}$ \\
\hline Failure mode ${ }^{b}$ & $0 / 0 / 10$ & $1 / 0 / 9$ & $7 / 0 / 3$ & $8 / 0 / 2$ \\
\hline UC & $10.0(2.4) \mathrm{d}$ & $12.3(2.0) \mathrm{e}$ & $15.2(1.7) f$ & $15.7(2.9) \mathrm{f}$ \\
\hline Failure mode & $0 / 0 / 10$ & $1 / 0 / 9$ & $6 / 0 / 4$ & $5 / 0 / 5$ \\
\hline
\end{tabular}


for those obtained at a stronger light intensity of 400 and $600 \mathrm{~mW} / \mathrm{cm}^{2}(p<0.050)$. With regard to the failure modes recorded for each group, the predominant failure mode was adhesive failure between dentin and the adhesive resin when a weaker light intensity of $200 \mathrm{~mW} / \mathrm{cm}^{2}$ or less was used. When the resin pastes were irradiated with stronger light intensities, the failure mode changed to cohesive failure.

SEM observations of the resin-dentin interface are shown in Figure 2. The dentin-resin interface of both groups showed excellent adaptation, with the formation of a transitional layer between the adhesive resin and tooth structure. The thickness of the adhesives was lesser for the specimens irradiated with a weaker light intensity of $<200 \mathrm{~mW} / \mathrm{cm}^{2}$.

\section{DISCUSSION}

The surface free energy of organic substances $\left(\gamma_{S}\right)$ generally has three components: dispersion $\left(\gamma_{S}^{d}\right)$, polar $\left(\gamma_{\mathrm{S}}^{\mathrm{p}}\right)$, and hydrogen $\left(\gamma_{\mathrm{S}}^{\mathrm{h}}\right)$ bonding. ${ }^{14}$ The dispersion force $\left(\gamma_{\mathrm{S}}^{\mathrm{d}}\right)$ represents the London interactions between apolar molecules, whereas the polar (nondispersion) force $\left(\gamma_{S}^{p}\right)$ represents the electric and metallic interactions in addition to the dipolar interactions. In addition to these two parameters of the $\gamma_{S}$, the hydrogen-bonding force $\left(\gamma_{S}^{\mathrm{h}}\right)$, which relates to the water and hydroxyl components, was calculated in the current study. Because the hydration of the adherend is of major importance to the wettability behavior related to dentin bonding, the polar interactions, including the dipole and hydrogen-bonding characteristics, should be accurately estimated for their interactions with water. A separate estimation of the dipole (polar) interactions, apart from the hydrogen-bonding interactions, may provide a novel insight into the mechanisms contributing to wettability as well as the bonding characteristics of the adhesives. According to Hata, Kitazaki, and Saito, ${ }^{16}$ the Fowkes equation for interfacial free energy can be extended to an interface that includes intermolecular interactions of polar and hydrogen bonding as well as dispersion bonding.

Changes in surface free energy are expressed by the sum of the geometrical means of the components. Contact angle data for the following three types of liquid were used for calculating the surface free energy: purely nonpolar (1-bromonaphthalene), polar (diiodomethane), and hydrogen-bonded (water). ${ }^{17}$ The $\gamma_{S}^{\mathrm{d}}$ values of the dentin surfaces remained relatively constant $\left(39.2\right.$ to $41.1 \mathrm{~mJ} \cdot \mathrm{m}^{-2}$ ) regardless of the adhesives used, and there were no significant

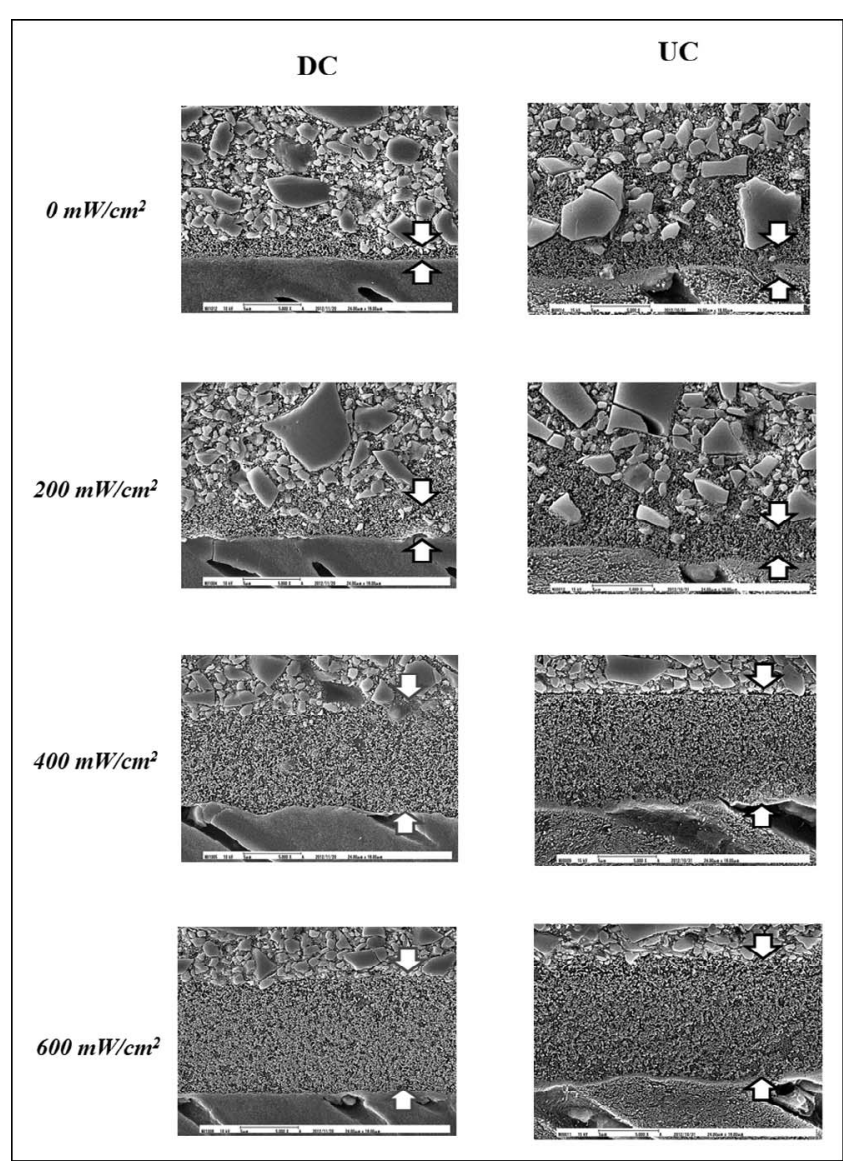

Figure 2. Representative SEM photomicrographs of the core buildup resin-dentin interface (original magnification, 5000X). Thickness of the adhesive was indicated by the white arrows in each SEM photomicrograph. The dentin-resin interface of both core build-up systems showed excellent adaptation, with the formation of a transitional layer between the adhesive resin and the tooth structure. The thickness of the adhesives was lesser for the specimens irradiated with a weaker light intensity of $<200 \mathrm{~mW} / \mathrm{cm}^{2}$.

differences among groups. ${ }^{18}$ The $\gamma_{\mathrm{S}}^{\mathrm{p}}$ values of all the specimens were relatively low (ranging from 0.7 to $5.6 \mathrm{~mJ} \cdot \mathrm{m}^{-2}$ ) and decreased with increasing light intensity. The $\gamma_{\mathrm{S}}^{\mathrm{p}}$ value involves the polar interaction, which is often called the nondispersion force, and refers to hydrophilic interactions. ${ }^{18}$ Functional monomers are capable of releasing protons and can potentially dissolve the smear layer and interact with the subadjacent intact dentin. ${ }^{19,20}$ This finding can be explained by the increase in the chemical reaction with the exposed hydroxyapatite crystals. Although the smear layer is hydrophobic, it holds water within. Moreover, it is porous, so initial partial spreading may have occurred by the infiltration of liquid through the layer. ${ }^{21}$ The hydrophilic monomers may form a complex structure with exposed collagen fibrils and partially demineralized dentin containing residual hydroxyapatite. A previous 
study that examined the chemical bonding efficacy of the functional monomers found that it had high potential for chemical bonding to hydroxyapatite and a clinically acceptable application time. ${ }^{22}$

The values for $\gamma_{\mathrm{S}}^{\mathrm{h}}$ ranged from 21.0 to $24.9 \mathrm{~mJ} \cdot \mathrm{m}^{-2}$ for the group without irradiation and from 8.8 to 14.8 $\mathrm{mJ} \cdot \mathrm{m}^{-2}$ for the groups irradiated with a light intensity of $400 \mathrm{~mW} / \mathrm{cm}^{2}$ and greater. Functional monomers have three distinct structural components: functional, spacer, and polymerizable groups. The functional group exhibits hydrophilic properties that enhance the wetting and demineralization of the tooth surface. ${ }^{23}$ The spacer group influences the properties of the monomer, including water solubility, and its size determines viscosity, wetting, and penetration behaviors. ${ }^{24}$ After light irradiation with stronger light intensities, the conversion of the polymerizable group of functional monomers was enhanced, leading to a more hydrophobic nature of the cured adhesives. The structure of the polymer network will be affected by the monomer composition, initiator, solvent, and light energy. ${ }^{25}$ Sufficient light energy may enhance the polymerization reaction and continue the double-bond conversion of resin monomers in the adhesives. Furthermore, the calcium salt of the functional monomer was highly insoluble and was able to resist ultrasonic rinsing with ethanol. According to the adhesion-decalcification concept, ${ }^{26}$ the less soluble the calcium salt of the acidic molecule, the more intense and stable the molecular adhesion to a hydroxyapatite-based substrate. The long carbonyl chain of 10-methacryloyloxydecyl dihydrogen phosphate renders this functional monomer relatively hydrophobic. ${ }^{24}$ Because the dentin surface was covered by such a hydrophobic layer after light irradiation with a stronger light intensity, relatively lower $\gamma_{\mathrm{S}}^{\mathrm{h}}$ values were obtained with the DC. Moreover, incomplete polymerization of adhesive would lead to residual water within the adhesive. ${ }^{27}$ Irradiation of the adhesive with a weaker light intensity may impair optimal formation of the cross-linking network of hydrophobic monomers due to the lower concentration of hydrophobic cross-linking monomers and incomplete polymerization of the bonding resin; this would lead to lower $\gamma_{S}^{\mathrm{h}}$ values of the adhesives irradiated with a weaker light intensity.

When the core build-up system was cured with a greater light intensity, the dentin bond strength values were higher. On the other hand, lower bond strengths were achieved when the core build-up systems were polymerized with a light intensity of $200 \mathrm{~mW} / \mathrm{cm}^{2}$ or less. These data may suggest inferior physical properties due to low double-bond conversion of resin monomers. ${ }^{28}$ From SEM observation of the dentin-resin interface, the thickness of the adhesive was much less in the group irradiated with a weaker light intensity. This indicates insufficient polymerization of the adhesive due to the lower light energy. Even if complete penetration into the demineralized dentin can be achieved, the degree of conversion of resin monomers may be impacted by the insufficient light energy. For the same reason, the mechanical properties of the material filled in the coronal region were better than those of the material filled in the apical region. ${ }^{4}$ Therefore, the properties of dual-cure core build-up resins may be different in different regions of the post cavity due to the decreased light energy in the deeper regions of the cavity; this may also affect regional bond strengths.

The adhesives of the core build-up systems were light irradiated directly during the bonding procedures and indirectly through the core build-up resins. Light intensity of the indirect light irradiation of adhesive layer may be affected by the shade and thickness of core build-up resins. It was reported that the indirect light irradiation through the resin composite contributes to higher dentin bond strength of self-etch adhesives. ${ }^{29}$ From the results of the present study, the type of core build-up system and the light intensity significantly influenced the bond strength, although there was no significant interaction between the two factors. The polymerization process of the bonding resin is influenced by the type and concentration of photo-initiators and catalysts used in the adhesives as well as light intensity. The photo-initiation system and light intensity of the curing unit might have a complex effect on dentin bond strength of the adhesives. Furthermore, one must consider that this in vitro study used flat dentin for the adherent surface, which might be different than the canal wall dentin because contraction stress induced by polymerization of core build-up resin causes reduction of bond strength in clinical situations. ${ }^{30}$

The adhesive systems used in this study are categorized as self-etching systems containing acidic functional monomer. When core build-up resin is irradiated, the hydrophobic resin matrix can copolymerize with the oxygen-inhibited layer produced on cured adhesives. ${ }^{31}$ Irradiation of the self-etch adhesives with a weaker light intensity retards the polymerization process, leading to the creation of a thicker oxygen-inhibited layer. Presumably, there would be remnants of acidic functional monomer with water and solvent in the oxygen-inhibited layer of self-etch adhesives. It is possible that the 
polymerization ability of the core build-up resin is affected by the acidic moieties because tertiary amines in the resin paste may be neutralized by the acidic functional monomers in the uncured adhesive. $^{32}$ The adhesive functional monomers affect the polymerization of $\mathrm{CQ} /$ amine catalysts, resulting in poor interaction with the resin paste. ${ }^{33}$ It has been reported that the thickness of the oxygen-inhibited layer of the adhesive may be changed by the total light energy supplied from a curing unit. When the total light energy supply increases, the degree of conversion increases and the thickness of the oxygen-inhibited layer decreases. ${ }^{34}$ Incompatibility between the adhesives and the core build-up resin does not occur under stronger light intensity conditions. However, improper polymerization occurs when the resin pastes are polymerized with weaker light intensities, including 0 and $200 \mathrm{~mW} / \mathrm{cm}^{2}$, which may lead to adverse interaction between the nucleophilic tertiary amine and acidic functional monomers as previously stated.

\section{CONCLUSIONS}

With regard to the dual-cure resin direct core buildup systems evaluated in this study, polymerization with a higher light intensity resulted in lower surface free energy of the adhesive-treated dentin surfaces because the conversion of the polymerizable group of functional monomers was enhanced. Sufficient light energy may enhance the polymerization reaction and continue the double-bond conversion of resin monomers in the adhesives, leading to higher bond strength to dentin. If the core build-up resin was polymerized with a light intensity of $200 \mathrm{~mW} /$ $\mathrm{cm}^{2}$ or less, a stronger hydrogen-bonding force was observed in the applied adhesives, leading to inferior bonding performance perhaps being due to the presence of water. The data suggest that the dentin bond strength and polymerization behavior of dualcure, direct core build-up systems are still affected by the light intensity of the curing unit.

\section{Acknowledgments}

This work was supported, in part, by a Grant-in-Aid for Scientific Research (C) 20592237; a Grant-in-Aid for Young Scientists (B) 19791415 from the Japan Society for the Promotion of Science; a grant from the Dental Research Center, Nihon University School of Dentistry; and the Sato Fund, Nihon University School of Dentistry.

\section{Conflict of Interest}

The authors of this manuscript certify that they have no proprietary, financial, or other personal interest of any nature or kind in any product, service, and/or company that is presented in this article.
(Accepted 16 December 2013)

\section{REFERENCES}

1. Stavridakis MM, Kakaboura AI, \& Krejci I (2005) Degree of remaining $\mathrm{C}=\mathrm{C}$ bonds, polymerization shrinkage and stresses of dual-cured core build-up resin composites Operative Dentistry 30(4) 443-452.

2. Oook S, Miyazaki M, Rikut A, \& Moore BK (2004) Influence of polymerization mode of dual-polymerized resin direct core foundation systems on bond strengths to bovine dentin Journal of Prosthetic Dentistry 92(3) 239-244.

3. Akgungor G, \& Akkayan B (2006) Influence of dentin bonding agents and polymerization modes on the bond strength between translucent fiber posts and three dentin regions within a post space Journal of Prosthetic Dentistry 95(5) 368-378.

4. Aksornmuang J, Nakajima M, Foxton RM, \& Tagami J (2006) Effect of prolonged photo-irradiation time of three self-etch systems on the bonding to root canal dentine Journal of Dentistry 34(6) 389-397.

5. Matsumoto M, Miura J, Takeshige F, \& Yatani H (2013) Mechanical and morphological evaluation of the bonddentin interface in direct resin core build-up method Dental Materials 29(3) 287-293.

6. Onay EO, Korkmaz Y, \& Kiremitci A (2010) Effect of adhesive system type and root region on the push-out bond strength of glass-fibre posts to radicular dentine International Endodontic Journal 43(4) 259-268.

7. Okuma M, Nakajima M, Hosaka K, Itoh S, Ikeda M, Foxton RM, \& Tagami J (2010) Effect of composite post placement on bonding to root canal dentin using 1-step self-etch dual-cure adhesive with chemical activation mode Dental Materials Journal 29(6) 642-648.

8. Rosales-Leal JI, Osorio R, Holgado-Terriza JA, CabrerizoVílchez MA, \& Toledano M (2001) Dentin wetting by four adhesive systems Dental Materials 17(6) 526-532.

9. Wang YJ, Zhang L, Chen JH, Goracci C, \& Ferrari M (2008) Influence of C-factor on the microtensile bond strength between fiber posts and resin luting agents Journal of Adhesive Dentistry 10(5) 385-391.

10. Aksornmuang J, Nakajima M, Senawongse P, \& Tagami J (2011) Effects of C-factor and resin volume on the bonding to root canal with and without fibre post insertion Journal of Dentistry 39(6) 422-429.

11. Carvalho RM, Manso AP, Geraldeli S, Tay FR, \& Pashley DH (2012) Durability of bonds and clinical success of adhesive restorations Dental Materials 28(1) 72-76.

12. Wege HA, Aguilar JA, Rodríguez-Valverde MÁ, Toledano M, Osorio R, \& Cabrerizo-Vílchez MÁ (2003) Dynamic contact angle and spreading rate measurements for the characterization of the effect of dentin surface treatments Journal of Colloid and Interface Science 263(1) 162-169.

13. Yassen GH, Platt JA, \& Hara AT (2011) Bovine teeth as substitute for human teeth in dental research: A review of literature Journal of Oral Science 53(3) 273-282.

14. Tsujimoto A, Iwasa M, Shimamura $Y$, Murayama R, Takamizawa T, \& Miyazaki M (2010) Enamel bonding of 
single-step self-etch adhesives: Influence of surface energy characteristics Journal of Dentistry 38(2) 123-130.

15. Asmussen E, \& Peutzfeldt A (2005) Resin composites: Strength of the bond to dentin versus surface energy parameters Dental Materials 21(11) 1039-1043.

16. Hata T, Kitazaki Y, \& Saito T (1987) Estimation of the surface energy of polymer solids Journal of Adhesion 21(3-4) 177-194.

17. Combe EC, Owen BA, \& Hodges JS (2004) A protocol for determining the surface free energy of dental materials Dental Materials 20(3) 262-268.

18. Glantz P-O (1971) The adhesiveness of teeth Journal of Colloid and Interface Science 37(2) 281-290.

19. Yoshida Y, Nagakane K, Fukuda R, Nakayama Y, Okazaki M, Shintani H, Inoue S, Tagawa Y, Suzuki K, De Munck J, \& Van Meerbeek B (2004) Comparative study on adhesive performance of functional monomers Journal of Dental Research 83(6) 454-458.

20. Nagakane K, Yoshida Y, Hirata I, Fukuda R, Nakayama Y, Shirai K, Ogawa T, Suzuki K, Van Meerbeek B, \& Okazaki M (2006) Analysis of chemical interaction of 4MET with hydroxyapatite using XPS Dental Materials Journal 25(4) 645-649.

21. Suyama Y, Lührs AK, De Munck J, Mine A, Poitevin A, Yamada T, Van Meerbeek B, \& Cardoso MV (2013) Potential smear layer interference with bonding of selfetching adhesives to dentin Journal of Adhesive Dentistry 15(4) 317-324.

22. Yoshida Y, Van Meerbeek B, Nakayama Y, Snauwaert J, Hellemans L, Lambrechts P, Vanherle G, \& Wakasa K (2000) Evidence of chemical bonding at biomaterial-hard tissue interfaces Journal of Dental Research $\mathbf{7 9 ( 2 )}$ 709-714.

23. Iwai $H$, \& Nishiyama $N$ (2012) Effect of calcium salt of functional monomer on bonding performance Journal of Dental Research 91(11) 1043-1048.

24. Van Landuyt KL, Snauwaert J, De Munck J, Peumans M, Yoshida Y, Poitevin A, Coutinho E, Suzuki K, Lambrechts P, \& Van Meerbeek B (2007) Systematic review of the chemical composition of contemporary dental adhesives Biomaterials 28(26) 3757-3785.

25. Ikemura K, \& Endo T (2010) A review of our development of dental adhesives-Effects of radical polymerization initiators and adhesive monomers on adhesion Dental Materials Journal 29(2) 109-121.
26. Yoshioka M, Yoshida Y, Inoue S, Lambrechts P, Vanherle G, Nomura Y, Okazaki M, Shintani H, \& Van Meerbeek B (2002) Adhesion/decalcification mechanisms of acid interactions with human hard tissues Journal of Biomedical Materials Research 59(1) 56-62.

27. Ariyoshi M, Nikaido T, Foxton RM, \& Tagami J (2010) Influence of filling technique and curing mode on the bond strengths of composite cores to pulpal floor dentin Dental Materials Journal 29(5) 562-569.

28. Seki N, Nakajima M, Kishikawa R, Hosaka K, Foxton RM, \& Tagami J (2011) The influence of light intensities irradiated directly and indirectly through resin composite to self-etch adhesives on dentin bonding Dental Materials Journal 30(3) 315-322.

29. Seki N, Nakajima M, Kishikawa R, Hosaka K, Foxton RM, \& Tagami J (2011) The influence of light intensities irradiated directly and indirectly through resin composite to self-etch adhesives on dentin bonding Dental Materials Journal 30(3) 315-322.

30. Bolhuis PB, de Gee AJ, Kleverlaan CJ, El Zohairy AA, \& Feilzer AJ (2006) Contraction stress and bond strength to dentin for compatible and incompatible combinations of bonding systems and chemical and light-cured core build-up resin composites Dental Materials 22(3) 223-233.

31. Koga K, Tsujimoto A, Ishii R, Iino M, Kotaku M, Takamizawa T, Tsubota K, \& Miyazaki M (2011) Influence of oxygen inhibition on the surface free-energy and dentin bond strength of self-etch adhesives European Journal of Oral Sciences 119(5) 395-400.

32. Giannini M, De Goes MF, Nikaido T, Shimada Y, \& Tagami J (2004) Influence of activation mode of dualcured resin composite cores and low-viscosity composite liners on bond strength to dentin treated with self-etching adhesives Journal of Adhesive Dentistry 6(4) 301-306.

33. Sanares AME, Itthagarun A, King NM, Tay FR, \& Pashley DH (2001) Adverse surface interactions between one-bottle light-cured adhesives and chemical-cured composites. Dental Materials 17(6) 542-556.

34. Kim J-S, Choi Y-H, Cho B-H, Son H-H, Lee I-B, Um C-M, \& Kim C-K (2006) Effect of light-cure time of adhesive resin on the thickness of the oxygen-inhibited layer and the microtensile bond strength to dentin Journal of Biomedical Materials Research Part B: Applied Biomaterials $\mathbf{7 8 ( 1 )}$ 115-123. 